\title{
The Evaluation of Phenolic Acids and Flavonoids Content and Antiprotozoal Activity of Eryngium Species Biomass Produced by Biotechnological Methods
}

\author{
Małgorzata Kikowska ${ }^{1, * \mathbb{D}}$, Justyna Chanaj-Kaczmarek ${ }^{2} \mathbb{D}$, Monika Derda ${ }^{3} \mathbb{D}$, Anna Budzianowska ${ }^{1}(\mathbb{D}$, \\ Barbara Thiem ${ }^{1}{ }^{\mathbb{D}}$, Halina Ekiert ${ }^{4}$ and Agnieszka Szopa ${ }^{4} \mathbb{D}$
}

Citation: Kikowska, M.;

Chanaj-Kaczmarek, J.; Derda, M.;

Budzianowska, A.; Thiem, B.; Ekiert,

H.; Szopa, A. The Evaluation of

Phenolic Acids and Flavonoids

Content and Antiprotozoal Activity

of Eryngium Species Biomass

Produced by Biotechnological

Methods. Molecules 2022, 27, 363.

https://doi.org/10.3390/

molecules 27020363

Academic Editor: Francesco Cacciola

Received: 3 December 2021

Accepted: 5 January 2022

Published: 7 January 2022

Publisher's Note: MDPI stays neutral with regard to jurisdictional claims in published maps and institutional affiliations.

Copyright: (C) 2022 by the authors. Licensee MDPI, Basel, Switzerland. This article is an open access article distributed under the terms and conditions of the Creative Commons Attribution (CC BY) license (https:// creativecommons.org/licenses/by/ $4.0 /)$.
1 Laboratory of Pharmaceutical Biology and Biotechnology, Department and Division of Practical Cosmetology and Skin Diseases Prophylaxis, Collegium Pharmaceuticum, Poznan University of Medical Sciences, 3 Rokietnicka St., 60-806 Poznań, Poland; abudzian@ump.edu.pl (A.B.); bthiem@ump.edu.pl (B.T.)

2 Department of Pharmacognosy, Collegium Pharmaceuticum, Poznan University of Medical Sciences, 3 Rokietnicka St., 60-806 Poznań, Poland; justyna.chanaj-kaczmarek@ump.edu.pl

3 Department of Biology and Medical Parasitology, Poznan University of Medical Sciences, 10 Fredry St., 61-701 Poznań, Poland; mderda@ump.edu.pl

4 Department of Pharmaceutical Botany, Collegium Medicum, Jagiellonian University, 9 Medyczna St., 30-688 Kraków, Poland; halina.ekiert@uj.edu.pl (H.E.); a.szopa@uj.edu.pl (A.S.)

* Correspondence: kikowska@ump.edu.pl

Abstract: Three species from the Eryngium L. genus-E. campestre, E. maritimum, and E. planum, plants with a rich chemical composition, were selected for phytochemical and biological studies. The applied biotechnological methods allowed to obtain the biomass of these rare or protected species in the form of multiplied shoots (stationary system) and roots cultured in a liquid medium (agitated system). In the extracts from the raw material obtained under in vitro conditions, the content of selected phenolic acids and flavonoids (HPLC-DAD method) as well as the total of polyphenols (Folin-Ciocalteu assay) were quantified. The highest amount of all phenolic compounds was found in extracts from E. planum roots $(950.90 \pm 33.52 \mathrm{mg} / 100 \mathrm{~g} \mathrm{d.w.})$, and the lowest from E. campestre roots ( $285.00 \pm 10.07 \mathrm{mg} / 100 \mathrm{~g}$ d.w.). The quantitatively dominant compound proved to be rosmarinic acid. The highest amounts were confirmed for E. planum root extract ( $694.58 \mathrm{mg} / 100 \mathrm{~g}$ d.w.), followed by E. planum (388.95 mg/100 g d.w.) and E. campestre (325.85 mg/100 g d.w.) shoot extracts. The total content of polyphenols was always increased in the biomass from in vitro cultures in comparison to the analogous organs of intact plants of each species. The obtained extracts were assessed for antiprotozoal activity against Acanthamoeba sp. The strength of biological activity of the extracts correlated with the content of phenolic compounds. To our knowledge, this is the first report on the amoebicidal activity of E. campestre, E. maritimum, and E. planum extracts from biomass produced by biotechnological methods.

Keywords: eryngo; in vitro cultures; extracts; phenolic acids; flavonoids; acanthamoebic activity

\section{Introduction}

Eryngium L. (Sea Holly, Eryngo) comprises about 230-250 species and is, therefore, the largest genus of the Saniculoideae subfamily from the Apiaceae family. This taxon is widespread in Central Asia, America, Central, and Southeast Europe, North Africa, and Australia [1,2]. Some of them, including E. campestre, E. maritimum, and E. planum, are described in Flora Europaea [3]. Among Polish taxa of the genus, E. maritimum is endangered and protected, E. planum and E. campestre are rare and can be found only in restricted regions [4].

Based on the review of the scientific literature up to now, the phytochemical investigations of those three Eryngium species revealed the presence of triterpenoid saponins, 
phenolic acids, flavonoids, coumarin derivatives, the essential oil, polyacetylenes, phytosterols, and ecdysteroids $[4,5]$. Some taxa have been used as ornamental, vegetable, and medicinal plants in folk medicine. These three species appearing in the Polish flora have been known from traditional medicine in Poland and Europe. The main raw materials herbs (Eryngii herba) and roots (Eryngii radix) are used as an antitussive, in various types of urinary tract diseases such as kidney and bladder stones, nephrosis or other kidney problems, employed to cure wounds, burns, pains, and hemorrhoids, moreover, applied as a remedy for snake venoms and scorpion stings [6].

Limited generative reproduction affected by low seed production, low germination, high juvenile mortality as well as habitats exploitation causes deficiency in the availability of plant material from natural sites. Plant in vitro cultures of those rare and endangered species as well as biotechnological methods of application may provide biomass with the enhanced accumulation of desired secondary metabolites without collecting plants from natural sites. Under natural conditions, the biosynthesis of secondary metabolites in plants is slow and generally very little effective. Methods of plant cultures in vitro enable strict control and optimization of biosynthesis. The project intends to achieve a constant and renewable plant biomass with a metabolic profile similar to ground plants, aimed at higher accumulation of specific secondary metabolites [6].

Parasitic free-living amoebae of the Acanthamoeba genus are cosmopolitan organisms widespread in the world-they occur in soil and air, as well as in fresh and salt water, but also in swimming pools, fountains, smears under the showers, bottled water, and lens fluids. Under favorable conditions, these amoebae can become pathogenic organisms-they can be the etiological factor of granulomatous amoebic encephalitis, keratitis acanthamoeba, as well as a cause of changes in many organs of humans and animals $[7,8]$. They access organisms via the respiratory tract, wounds, lesions, or skin ulcerations. Due to the fact that the life cycle of free-living amoebae is relatively simple, and their isolation and axenization do not pose any major difficulties, it is possible to culture them in in vitro conditions and study the influence of compounds, fractions, or plant extracts on the antiprotozoal activity against Acanthamoeba sp. [7-9].

The aim of the present study was to evaluate the phenolic compounds content and to investigate the in vitro antiamoebic activity of the extracts obtained from biomass produced by biotechnological methods (shoot and root in vitro culture) of E. campestre, E. maritimum, and E. planum on the growth and development of trophozoites.

\section{Results and Discussion}

The introduction of selected Eryngium species (E. campestre, E. maritimum, and E. planum) into in vitro culture conditions was previously described [10-12]. Material for biotechnological, phytochemical, and biological research came from stabilized cultures of the described species. Briefly, initial shoot cultures originated from aseptic seedling explants (fruits obtained from plants from natural sites) of E. campestre and E. planum, or stem fragments with nodes (young plants collected from a botanical garden) of E. maritimum. Despite many attempts, it was not possible to obtain seedlings from axenic seeds of E. maritimum continuing their development in in vitro cultures. For the subsequent growth of shoot cultures and the regeneration of the largest number of shoots, the media were supplemented with plant growth regulators. Adventitious root cultures were initiated from explants derived from rooted plantlets, on a solid medium in the process of micropropagation (Figure 1).

Shoot multiplication by the development of axillary buds of three Eryngium species is a fast and effective strategy for obtaining a relatively large number of new shoots (Table 1). The studied species were characterized by a high shoot induction coefficient (96.3-100\%). For these species, it was possible to obtain a high number of shoots (except for E. maritimum), which guarantees obtaining the necessary biomass for phytochemical and biological analyzes. 

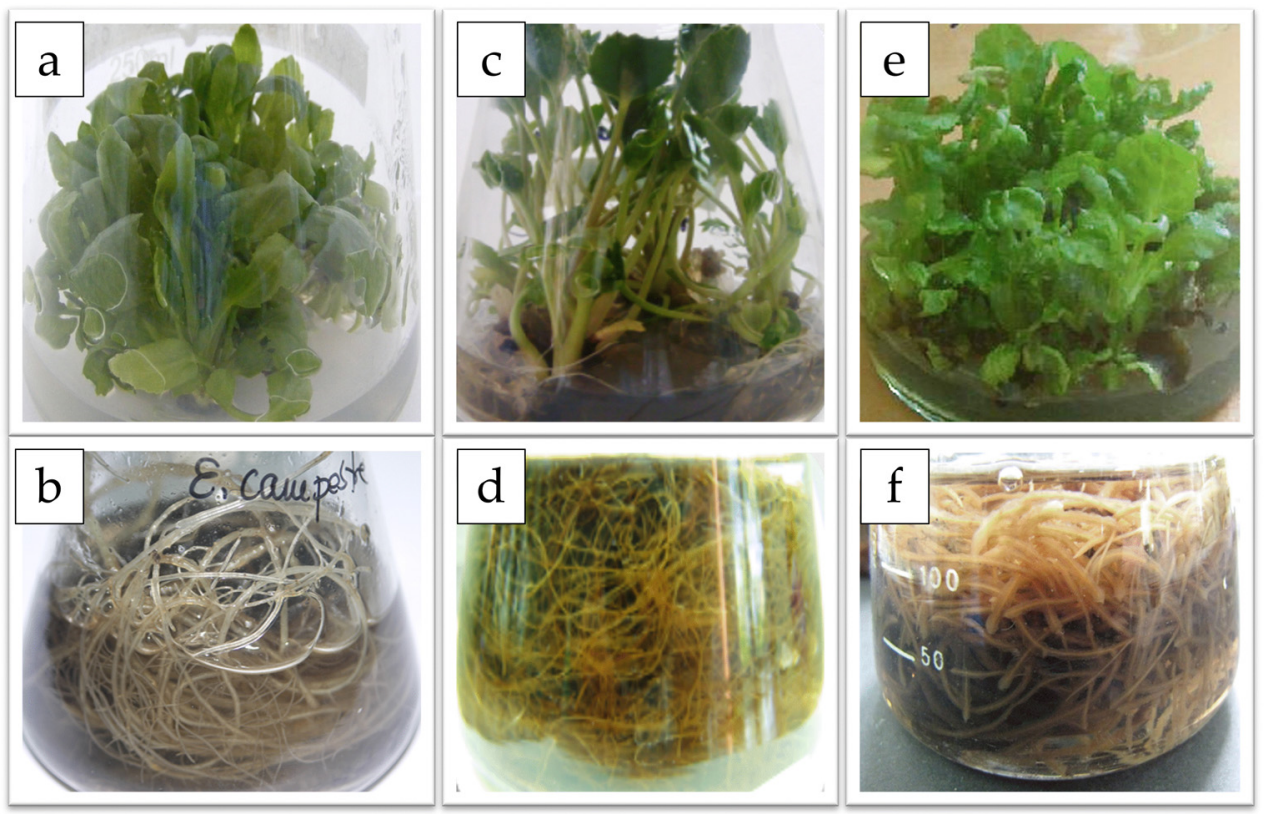

Figure 1. In vitro shoot and root cultures of: (a,b) Eryngium campestre L.; (c,d) Eryngium maritimum L.; (e,f) Eryngium planum L.

Table 1. The growth parameters of stabilized in vitro shoot cultures of Eryngium species.

\begin{tabular}{ccccc}
\hline Species Studied & $\begin{array}{c}\text { Explants that } \\
\text { Proliferated } \\
\text { Buds (\%) }\end{array}$ & $\begin{array}{c}\text { Shoot Number } \\
\text { per Explant (SE) }\end{array}$ & $\begin{array}{c}\text { Shoot Length } \\
\text { (cm SE) }\end{array}$ & $\begin{array}{c}\text { Leaf Number } \\
\text { Per Shoot (SE) }\end{array}$ \\
\hline E. campestre & 100 & $11.34 \pm 0.46^{\mathrm{b}}$ & $3.56 \pm 0.12^{\mathrm{a}}$ & $5.15 \pm 0.20^{\mathrm{a}}$ \\
E. maritimum & 96.3 & $4.1 \pm 0.30^{\mathrm{c}}$ & $3.1 \pm 0.03^{\mathrm{b}}$ & $3.90 \pm 0.07^{\mathrm{a}}$ \\
E. planum & 100 & $14.56 \pm 0.20^{\mathrm{a}}$ & $4.52 \pm 0.04^{\mathrm{a}}$ & $5.29 \pm 0.04^{\mathrm{a}}$ \\
\hline
\end{tabular}

The results are presented as the mean \pm SE of three independent experiments with 30 explants per treatment. Mean values within a column with the same letter are not significantly different at $p<0.05$ using Duncan's multiple range test. The first letter of the alphabet for the highest values, the next for statistically significant decreasing values.

The shoots were characterized by the correct morphology and physiology, did not show hyperhydricity, necrosis, or callus formation at the shoot base, therefore, these raw materials can be described as homogeneous and of high quality (Figure 1).

The presence of cytokinin in the medium was an important factor in the process of shoot multiplication. According to the literature, 6-benzyladenine (whether used alone or in combination with auxin) influenced the number of micro-shoots formed in in vitro cultures. This relationship was also observed for other species belonging to the Apiaceae family: Thapsia garganica L. [13], Arracacia xanthorrhiza Bancr. [14], or Anethum graveolens L. [15].

Roots play an important role not only in plant growth and development but also constitute a place of accumulation of secondary metabolites, in large part also those useful from a pharmaceutical point of view. Moreover, the adventitious roots show significant productivity, which is why they are often an important source of these substances [16]. In this study, a method of obtaining and cultivating adventitious roots in liquid media was developed for the domestic species of Eryngium. The main pharmaceutical raw material Eryngium is the root of intact plants, rich in secondary metabolites, therefore, in vitro cultures of these organs were established.

In this experiment, fragments of roots regenerated in in vitro cultures of micropropagated plants were used to establish root lines agitated in liquid media (Figure 1). Approximately $2 \mathrm{~cm}$ long sections of main roots containing a growth tip with apical meristem were taken and grown in liquid MS media supplemented with selected auxin-indole-3-acetic 
acid (IAA). The adventitious roots gradually grew in length and the lateral root system developed. The roots of two species-E. campestre and E. planum-grew fastest; much worse-E. maritimum (Table 2). However, the fresh and dry weight gains were relatively small compared to other species.

Table 2. The root biomass ( $\mathrm{g} \pm \mathrm{SE}$ ) of Eryngium spp. in MS liquid medium after 24 weeks of in vitro culture.

\begin{tabular}{ccc}
\hline Species Studied & Fresh Weight $[\mathrm{g}]$ & Dried Weight $[\mathrm{g}]$ \\
\hline E. campestre & $27.1 \pm 0.60^{\mathrm{a}}$ & $5.8 \pm 0.21^{\mathrm{a}}$ \\
E. maritimum & $16.4 \pm 0.78^{\mathrm{b}}$ & $4.1 \pm 0.43^{\mathrm{b}}$ \\
E. planum & $25.1 \pm 1.45^{\mathrm{a}}$ & $5.8 \pm 0.16^{\mathrm{a}}$
\end{tabular}

The results are presented as the mean \pm SE of three independent experiments with 5 explants per treatment. Mean values within a column with the same letter are not significantly different at $p<0.05$ using Duncan's multiple range test. The first letter of the alphabet for the highest values, the next for statistically significant decreasing values.

Under the HPLC-DAD analyses in the studied methanolic extracts of in vitro Eryngium spp. Cultures, the qualitative differences were noted (Table 3). In E. campestre, eight phenolic acids were present: chlorogenic, ferulic, 3,4-dihydroxyphenylacetic, caffeic (not detected in roots), protocatechuic, rosmarinic, syringic, 4-feruloylquinic acid, and 4-dihydroxybenzoic acids, and 5 flavonoids: kaempferol, quercitrin (not detected in shoots), rutoside (not detected in roots), quercetin, and astragalin. In E. maritimum were present nine phenolic acids: chlorogenic, ferulic, 3,4-dihydroxyphenylacetic, caffeic (not detected in roots), protocatechuic, rosmarinic, syringic, vanillic, 4-feruloylquinic acid and 4-dihydroxybenzoic acids, and tree flavonoids: kaempferol, quercitrin and rutoside). In E. planum, nine phenolic acids were present: chlorogenic, isochlorogenic, ferulic, 3,4-dihydroxyphenylacetic, caffeic, protocatechuic, rosmarinic, syringic, vanillic (not detected in roots), and 4-feruloylquinic acid, and tree flavonoids: kaempferol, quercitrin, and astragalin. Most of these acids (except chlorogenic, caffeic, rosmarinic and ferulic acids) were for the first time detected and quantified in the raw materials of these species (Table 3).

Undoubtedly, rosmarinic acid (RA) was the phenolic acid found in the highest concentration in all of the tested shoot and root in vitro cultures of Eryngium spp. The richest source of RA, based on our estimations, were root $(694.58 \mathrm{mg} / 100 \mathrm{~g}$ d.w.) and shoot ( $388.95 \mathrm{mg} / 100 \mathrm{~g}$ d.w.) cultures of E. planum (Table 3). Within all detected phenolic compounds, RA was quantitatively dominant also in E. maritimum $(181.27 \mathrm{mg} / 100 \mathrm{~g}$ d.w.- - root; $174.51 \mathrm{mg} / 100 \mathrm{~g}$ d.w.- - shoot cultures) and in E. campestre (100.91 mg/100 g d.w.- root; $325.85 \mathrm{mg} / 100 \mathrm{~g}$ d.w.- -shoot cultures) (Table 3). RA was found most notably also before in Eryngium species, especially in shoots and roots of intact plants and micropropagated in vitro plantlets: E. campestre [12], E. maritimum [11], and E. planum [10]. The qualitative screening analysis of Eryngium genus performed by the team of Le Claire revealed the presence of rosmarinic acid in the root extracts of 11 Eryngium species [17].

Chlorogenic acid and 3,4-dihydroxyphenylacetic acid were found in much lower concentrations than RA, but relatively higher than for other phenolic acids. Three conjugates of caffeic acid and quinic acid namely neochlorogenic acid (5-caffeoylquinic acid), chlorogenic acid (3-caffeoylquinic acid), and isochlorogenic acid (3,5-dicaffeoylquinic acid) were demonstrated: in shoots and roots obtained from ground plants and in vitro-propagated E. campestre [12,18], E. maritimum [11,18], and E. planum $[10,18]$.

Comparing the total phenolic acids contents estimated with the HPLC method, E. planum root cultures proved to be the richest source of these compounds $(924.21 \mathrm{mg} /$ $100 \mathrm{~g}$ d.w.), mainly due to the high content of RA (Table 3). Moreover, high phenolic acid total contents were detected for E. campestre (739.26 mg/100 g d.w.) and E. planum (729.10 mg/100 g d.w.) shoot cultures (Table 3). 
Table 3. The contents (mg/100 g d.w. \pm SD) of estimated phenolic acids and flavonoids in the shoot and root in vitro cultures of different Eryngium species.

\begin{tabular}{|c|c|c|c|c|c|c|}
\hline \multirow[t]{2}{*}{ Compounds } & \multicolumn{2}{|c|}{ E. campestre } & \multicolumn{2}{|c|}{ E. maritimum } & \multicolumn{2}{|c|}{ E. planum } \\
\hline & Shoot Culture & Root Culture & Shoot Culture & Root Culture & Shoot Culture & Root Culture \\
\hline \multicolumn{7}{|l|}{ Phenolic acid } \\
\hline Chlorogenic acid & $154.47 \pm 5.44^{\mathrm{a}}$ & $13.20 \pm 0.47^{\mathrm{e}}$ & $30.51 \pm 1.08^{\mathrm{d}}$ & $140.56 \pm 4.95^{b}$ & $107.91 \pm 3.80^{c}$ & $99.67 \pm 3.51^{\mathrm{c}}$ \\
\hline Isochlorogenic acid & n.d. & n.d & n.d. & n.d. & $46.30 \pm 1.63^{\mathrm{a}}$ & $17.34 \pm 0.61^{\mathrm{b}}$ \\
\hline Ferulic acid & $23.25 \pm 0.82^{b}$ & $9.35 \pm 0.33^{b}$ & $7.76 \pm 0.27^{\mathrm{d}}$ & $8.33 \pm 0.29^{c}$ & $3.17 \pm 0.11^{\mathrm{f}}$ & $3.51 \pm 0.12^{\mathrm{e}}$ \\
\hline 3,4-Dihydroxyphenylacetic acid & $88.88 \pm 3.13^{b}$ & $50.91 \pm 1.79^{c}$ & $40.76 \pm 1.44^{\mathrm{d}}$ & $108.92 \pm 3.84^{\mathrm{a}}$ & $104.05 \pm 3.67^{\mathrm{a}}$ & $52.21 \pm 1.84^{\mathrm{c}}$ \\
\hline Caffeic acid & $4.03 \pm 0.14^{\mathrm{e}}$ & n.d. & $4.77 \pm 0.17^{\mathrm{d}}$ & $8.81 \pm 0.31^{\mathrm{c}}$ & $16.51 \pm 0.58^{a}$ & $14.78 \pm 0.52^{\mathrm{b}}$ \\
\hline Protocatechuic acid & $8.12 \pm 0.29^{\mathrm{a}}$ & $1.81 \pm 0.06^{\mathrm{e}}$ & $3.61 \pm 0.13^{d}$ & $7.41 \pm 0.26^{\mathrm{b}}$ & $8.57 \pm 0.30^{\mathrm{a}}$ & $4.07 \pm 0.14^{c}$ \\
\hline Rosmarinic acid (RA) & $325.85 \pm 11.48^{c}$ & $100.91 \pm 3.56^{\mathrm{e}}$ & $174.51 \pm 6.15^{\mathrm{d}}$ & $181.27 \pm 6.39^{\mathrm{d}}$ & $388.95 \pm 13.70^{b}$ & $694.58 \pm 24.47^{a}$ \\
\hline Syringic acid & $0.99 \pm 0.04^{c}$ & $5.45 \pm 0.19^{a}$ & $1.87 \pm 0.07^{b}$ & $1.86 \pm 0.07^{b}$ & $0.37 \pm 0.01^{\mathrm{e}}$ & $0.88 \pm 0.03^{\mathrm{d}}$ \\
\hline Vanillic acid & n.d. & n.d. & $2.54 \pm 0.09^{b}$ & $2.34 \pm 0.08^{c}$ & $5.68 \pm 0.20^{\mathrm{a}}$ & n.d. \\
\hline 4-Feruloylquinic acid & $9.83 \pm 0.35^{\mathrm{d}}$ & $46.90 \pm 1.65^{\mathrm{b}}$ & $8.44 \pm 0.30^{\mathrm{e}}$ & $64.96 \pm 2.29^{a}$ & $47.59 \pm 1.68^{b}$ & $38.17 \pm 1.34^{\mathrm{c}}$ \\
\hline 4-Dihydroxybenzoic acid & $122.84 \pm 4.33^{\mathrm{a}}$ & n.d. & $7.56 \pm 0.27^{b}$ & n.d. & n.d. & n.d. \\
\hline Sum of phenolic acids & $738.26 \pm 26.02^{b}$ & $228.53 \pm 8.05^{\mathrm{e}}$ & $282.33 \pm 9.90^{\mathrm{d}}$ & $524.46 \pm 20.77^{c}$ & $729.10 \pm 25.68^{b}$ & $925.21 \pm 32.58^{a}$ \\
\hline \multicolumn{7}{|l|}{ Flavonoids } \\
\hline Kaempferol & $14.53 \pm 0.51^{\mathrm{a}}$ & $5.85 \pm 0.20^{\mathrm{e}}$ & $13.10 \pm 0.46^{\mathrm{b}}$ & $6.41 \pm 0.22^{\mathrm{d}}$ & $3.71 \pm 0.13^{\mathrm{f}}$ & $8.82 \pm 0.31^{c}$ \\
\hline Quercitrin & n.d. & $21.45 \pm 0.75^{\mathrm{a}}$ & $6.95 \pm 0.24^{\mathrm{d}}$ & $10.55 \pm 0.37^{c}$ & $11.25 \pm 0.40^{\mathrm{c}}$ & $14.41 \pm 0.51^{\mathrm{b}}$ \\
\hline Rutoside & $29.51 \pm 1.04^{\mathrm{a}}$ & n.d. & $14.32 \pm 0.50^{\mathrm{b}}$ & $12.16 \pm 0.43^{\mathrm{c}}$ & n.d. & n.d. \\
\hline Quercetin & $6.92 \pm 0.24^{b}$ & $22.96 \pm 0.81^{\mathrm{a}}$ & n.d. & n.d. & n.d. & n.d. \\
\hline Astragalin & $57.05 \pm 1.44^{\mathrm{a}}$ & $6.21 \pm 0.26^{c}$ & n.d. & n.d. & $15.49 \pm 0.63^{b}$ & $2.46 \pm 0.12^{\mathrm{d}}$ \\
\hline Sum of flavonoids & $108.01 \pm 3.23^{a}$ & $56.47 \pm 2.02^{b}$ & $34.37 \pm 1.20^{c}$ & $29.12 \pm 1.02^{\mathrm{d}}$ & $30.45 \pm 1.16^{\mathrm{d}}$ & $25.69 \pm 0.94 \mathrm{e}^{\mathrm{e}}$ \\
\hline $\begin{array}{l}\text { Sum of phenolic acids and } \\
\text { flavonoids }\end{array}$ & $846.27 \pm 29.25^{b}$ & $285.00 \pm 10.07^{\mathrm{f}}$ & $316.70 \pm 11.10^{\mathrm{e}}$ & $553.65 \pm 21.79^{\mathrm{d}}$ & $759.55 \pm 26.84^{\mathrm{c}}$ & $950.90 \pm 33.52^{a}$ \\
\hline
\end{tabular}

n.d.-not detected. Mean values within a raw with the same letter are not significantly different at $p<0.05$ using Duncan's multiple range test. The first letter of the alphabet for the highest values, the next for statistically significant decreasing values.

The flavonoid estimations with HPLC showed also quantitative differences within individual compounds depending on studied species as well as Eryngium spp. (Table 3). Quantitative analyzes generally show that shoots from in vitro cultures have a higher content of flavonoids than roots grown under the same conditions. The main flavonoid for E. campestre was astragalin $(57.05 \mathrm{mg} / 100 \mathrm{~g}$ d.w.-shoots, $6.21 \mathrm{mg} / 100 \mathrm{~g}$ d.w.—roots), for E. maritimum —rutoside ( $14.32 \mathrm{mg} / 100 \mathrm{~g}$ d.w.-shoots, $12.16 \mathrm{mg} / 100 \mathrm{~g}$ d.w.—roots) and for E. planum was quercitrin (11.25 mg/100 g d.w.—shoots, $14.41 \mathrm{mg} / 100 \mathrm{~g}$ d.w.-roots) (Table 3). Comparing the total contents of flavonoids in in vitro cultures of analogous organs of Eryngium spp., a trend according to the formula can be noticed: E. campestre $>$ E. maritimum $>$ E. planum. Summing up, the most valuable source of flavonoids is the in vitro shoots of E. campestre, mainly due to the very high content of astragalin (Table 3).

Flavonoids characterized in these species concern plants from their natural sites. The phytochemical study initiated by the team of Hiller and Leokadia in the 1980s revealed the presence of two derivatives of kaempferol in the aerial part of E. planum L. $[19,20]$. In more widely studied E. campestre L., the following compounds were iden-

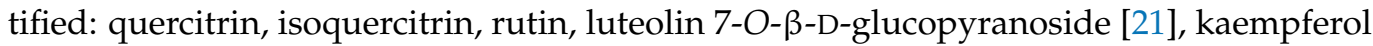
$3-O-\beta$-D-(2'-p-E-hydroxycinnamoyl)-glucopyranoside, and kaempferol 3-O- $\beta$-D-(2'- $p-Z-$ hydroxycinnamoyl)-glucopyranoside [22]. These findings encourage the investigation of the aerial part of E. campestre L. and in consequence 11 flavonol compounds were isolated. Three quercetin glycosides, five isorhamnetin glycosides, and three myricetin glycosides were elucidated by spectroscopic and chemical methods employing UV-visible spectrophotometer, MS, and NMR spectrometer [23]. E. maritimum L. contains mainly astragalin, 3- $\beta$ D-glucopyranoside7-O-L-rhamnopyranoside, kaempferol, and isoquercitrin [24]. Polyphenolic compounds identified by Conea et al. in the Eryngium (E. planum L., E. campestre L., 
and E. maritimum L.) tinctures were isoquercitrin, quercitrin, rutoside, and kaempferol [18]. Through the multiplication of Eryngium biomass in vitro, it became possible to supplement the knowledge on the presence and content of phenolic compounds in the raw materials of these species.

Based on the comparison of total phenolic compounds contents estimated with the HPLC method, the richest source of these compounds was root cultures of E. planum (950.90 mg/100 g d.w.) and shoot cultures of E. campestre (846.27 mg/100 g d.w.) (Table 3).

Quantitative studies of the content of polyphenols using spectrophotometric methods according to the modified method of Meng et al. [25] with the use of the Folin-Ciocalteu reagent were carried out comparatively for the raw materials of intact plants and organs (shoots and roots) from in vitro cultures of three Eryngium species (Table 4).

Table 4. Total phenolic content in Eryngium species dry plant material evaluated by Folin-Ciocalteau method, expressed as gallic acid equivalent ( $\mathrm{mg} / 100 \mathrm{~g})$.

\begin{tabular}{|c|c|c|c|}
\hline Species Studied & Plant Origin & Organ & $\begin{array}{l}\text { Polyphenols Content } \\
\text { (mg GAE/100 g) }\end{array}$ \\
\hline \multirow{4}{*}{ E. campestre } & Intact plant & Shoots & $945 \pm 4^{\mathrm{f}}$ \\
\hline & In vitro culture & Shoots & $1507 \pm 11^{b}$ \\
\hline & Intact plant & Roots & $1030 \pm 20^{e}$ \\
\hline & In vitro culture & Roots & $2254 \pm 10^{a}$ \\
\hline \multirow{4}{*}{ E. maritimum } & Intact plant & Shoots & $1120 \pm 17^{d}$ \\
\hline & In vitro culture & Shoots & $1551 \pm 17^{b}$ \\
\hline & Intact plant & Roots & $150 \pm 1^{h}$ \\
\hline & In vitro culture & Roots & $1179 \pm 4^{\mathrm{d}}$ \\
\hline \multirow{4}{*}{ E. planum } & Intact plant & Shoots & $1221 \pm 12^{\mathrm{c}}$ \\
\hline & In vitro culture & Shoots & $1584 \pm 18^{b}$ \\
\hline & Intact plant & Roots & $245 \pm 1^{g}$ \\
\hline & In vitro culture & Roots & $1507 \pm 11^{b}$ \\
\hline
\end{tabular}

The results are presented as the mean \pm SD of six independent repetitions. Mean values within a column with the same letter are not significantly different at $p<0.05$ using Duncan's multiple range test. The first letter of the alphabet for the highest values, the next for statistically significant decreasing values.

The content of the sum of polyphenols in the tested raw materials was always higher in the biomass from in vitro cultures than in the analogous organs from intact plants for selected species (Table 4). In particular, the root biomass from in vitro cultures was characterized by a much higher polyphenol content than the roots of intact plants. The highest content of total polyphenols (2254 of gallic acid equivalent (mg/100 g)) was found in the roots of in vitro cultures of E. campestre, which is consistent with the observation of their morphology-these were the youngest roots, characterized by a large number of lateral roots.

The antiprotozoal action of the extracts obtained from Eryngium, both from in vitro shoot and root cultures, was evaluated in vitro against Acanthamoeba sp. strain Ac55. The results of the study indicated that the extracts inhibited the growth of trophozoites to varying degrees. The dependence of the effect on the extract concentration and treatment time was noted (Tables 5-8).

In the case of E. campestre, the strongest effect was observed for in vitro shoot culture (Table 5). The higher sample concentration was applied, the more effective activity was observed in comparison with the control during the same time interval. It can be noticed that the shoot extract activity was potent from the beginning of the treatment and remained at a similar level $(5.0 \mathrm{mg} / \mathrm{mL})$ or a significantly lower level $(0.5 \mathrm{mg} / \mathrm{L}$ and $2.5 \mathrm{mg} / \mathrm{L}) \mathrm{during}$ the next days, while the activity of the root extract increased with the time of treatment (0.5 $\mathrm{mg} / \mathrm{L}$ and $2.5 \mathrm{mg} / \mathrm{L})$. 
Table 5. Effect of extract from Eryngium campestre shoot and root in vitro cultures on inhibition of Acanthamoeba trophozoites during four days treatment.

\begin{tabular}{ccccccc}
\hline \multirow{2}{*}{$\begin{array}{c}\text { Extracts } \\
\text { Concentration }\end{array}$} & \multicolumn{5}{c}{ Duration of Treatment [days] } \\
\cline { 2 - 7 } & \multicolumn{2}{c}{ 2nd Day } & \multicolumn{2}{c}{ 3rd Day } \\
\hline Shoot culture & $\mathrm{MN} \pm \mathrm{SD}$ & $\mathrm{GI}[\%]$ & $\mathrm{MN} \pm \mathrm{SD}$ & $\mathrm{GI}[\%]$ & $\mathrm{MN} \pm \mathrm{SD}$ & 4th Day \\
Control & $10.11 \pm 2.05^{\mathrm{a}, \mathrm{C}}$ & 0 & $15.72 \pm 3.36^{\mathrm{a}, \mathrm{B}}$ & 0 & $38.39 \pm 7.77^{\mathrm{a}, \mathrm{A}}$ & 0 \\
$0.5 \mathrm{mg} / \mathrm{mL}$ & $5.81 \pm 2.07^{\mathrm{b}, \mathrm{B}}$ & 42.54 & $9.06 \pm 2.09^{\mathrm{b}, \mathrm{B}}$ & 42.37 & $23.88 \pm 6.49^{\mathrm{b}, \mathrm{A}}$ & 37.80 \\
$2.5 \mathrm{mg} / \mathrm{mL}$ & $1.71 \pm 1.18^{\mathrm{c}, \mathrm{B}}$ & 83.09 & $4.33 \pm 1.63^{\mathrm{c}, \mathrm{B}}$ & 72.46 & $10.75 \pm 3.47^{\mathrm{d}, \mathrm{A}}$ & 72.00 \\
$5.0 \mathrm{mg} / \mathrm{mL}$ & $0.72 \pm 0.65^{\mathrm{d}, \mathrm{A}}$ & 92.88 & $1.11 \pm 0.81^{\mathrm{d}, \mathrm{A}}$ & 92.94 & $1.41 \pm 1.15^{\mathrm{e}, \mathrm{A}}$ & 96.33 \\
Root culture & $\mathrm{MN} \pm \mathrm{SD}$ & $\mathrm{GI}[\%]$ & $\mathrm{MN} \pm \mathrm{SD}$ & $\mathrm{GI}[\%]$ & $\mathrm{MN} \pm \mathrm{SD}$ & $\mathrm{GI}[\%]$ \\
Control & $11.11 \pm 1.85^{\mathrm{a}, \mathrm{C}}$ & 0 & $20.33 \pm 3.80^{\mathrm{a}, \mathrm{B}}$ & 0 & $27.81 \pm 3.64^{\mathrm{a}, \mathrm{A}}$ & 0 \\
$0.5 \mathrm{mg} / \mathrm{mL}$ & $10.28 \pm 2.84^{\mathrm{ab}, \mathrm{B}}$ & 7.48 & $15.50 \pm 2.91^{\mathrm{ab}, \mathrm{AB}}$ & 23.76 & $20.5 \pm 3.80^{\mathrm{a}, \mathrm{A}}$ & 27.55 \\
$2.5 \mathrm{mg} / \mathrm{mL}$ & $7.78 \pm 2.25^{\mathrm{ab}, \mathrm{B}}$ & 29.98 & $11.42 \pm 3.07^{\mathrm{b}, \mathrm{AB}}$ & 43.83 & $12.44 \pm 3.28^{\mathrm{b}, \mathrm{A}}$ & 55.27 \\
$5.0 \mathrm{mg} / \mathrm{mL}$ & $6.23 \pm 2.28^{\mathrm{b}, \mathrm{A}}$ & 43.93 & $7.20 \pm 2.14^{\mathrm{b}, \mathrm{A}}$ & 64.59 & $7.93 \pm 5.66^{\mathrm{b}, \mathrm{A}}$ & 71.49 \\
\hline
\end{tabular}

Mean values within a raw (capital letters) and a column (small letters) with the same letter are not significantly different at $p<0.05$ using Duncan's multiple range test. The first letter of the alphabet for the highest values, the next for statistically significant decreasing values. $n=18$. MN—mean number of trophozoites; GI-growth inhibition.

Table 6. Effect of extract from Eryngium maritimum shoot and root in vitro culture on inhibition of Acanthamoeba trophozoites during four days treatment.

\begin{tabular}{|c|c|c|c|c|c|c|}
\hline \multirow{3}{*}{$\begin{array}{c}\begin{array}{c}\text { Extracts } \\
\text { Concentration }\end{array} \\
\text { Shoot culture }\end{array}$} & \multicolumn{6}{|c|}{ Duration of Treatment [days] } \\
\hline & \multicolumn{2}{|c|}{ 2nd Day } & \multicolumn{2}{|c|}{ 3rd Day } & \multicolumn{2}{|c|}{ 4th Day } \\
\hline & $\mathrm{MN} \pm \mathrm{SD}$ & GI [\%] & $\mathrm{MN} \pm \mathrm{SD}$ & GI [\%] & $\mathrm{MN} \pm \mathrm{SD}$ & GI [\%] \\
\hline Control & $5.89 \pm 2.71^{\mathrm{a}, \mathrm{C}}$ & 0 & $19.72 \pm 3.40^{\mathrm{a}, \mathrm{B}}$ & 0 & $27.22 \pm 4.59^{\mathrm{a}, \mathrm{A}}$ & 0 \\
\hline $0.5 \mathrm{mg} / \mathrm{mL}$ & $4.53 \pm 2.63^{a b, c}$ & 23.09 & $11.02 \pm 1.71^{\mathrm{b}, \mathrm{B}}$ & 34.49 & $17.40 \pm 4.17^{\mathrm{b}, \mathrm{A}}$ & 36.05 \\
\hline $2.5 \mathrm{mg} / \mathrm{mL}$ & $3.72 \pm 1.59 \mathrm{ab}, \mathrm{C}$ & 36.85 & $7.08 \pm 0.86^{c, B}$ & 44.10 & $14.00 \pm 2.28^{b, A}$ & 48.57 \\
\hline $5.0 \mathrm{mg} / \mathrm{mL}$ & $2.00 \pm 1.15^{\mathrm{b}, \mathrm{A}}$ & 66.05 & $2.17 \pm 1.57^{\mathrm{d}, \mathrm{A}}$ & 89.00 & $2.27 \pm 1.62^{\mathrm{c}, \mathrm{A}}$ & 91.67 \\
\hline Root culture & $\mathrm{MN} \pm \mathrm{SD}$ & GI [\%] & $\mathrm{MN} \pm \mathrm{SD}$ & GI [\%] & $\mathrm{MN} \pm \mathrm{SD}$ & GI $[\%]$ \\
\hline control & $5.89 \pm 2.71^{\mathrm{a}, \mathrm{B}}$ & 0 & $9.72 \pm 3.40^{\mathrm{a}, \mathrm{B}}$ & 0 & $17.22 \pm 4.09^{\mathrm{a}, \mathrm{A}}$ & 0 \\
\hline $0.5 \mathrm{mg} / \mathrm{mL}$ & $4.45 \pm 1.28^{\mathrm{a}, \mathrm{B}}$ & 24.32 & $7.44 \pm 3.04^{\mathrm{a}, \mathrm{AB}}$ & 23.46 & $11.88 \pm 4.01^{\mathrm{a}, \mathrm{A}}$ & 31.02 \\
\hline $2.5 \mathrm{mg} / \mathrm{mL}$ & $2.38 \pm 0.38^{b, B}$ & 59.60 & $1.00 \pm 0.50^{\mathrm{b}, \mathrm{A}}$ & 89.72 & $2.99 \pm 2.45^{\mathrm{b}, \mathrm{A}}$ & 92.61 \\
\hline $5.0 \mathrm{mg} / \mathrm{mL}$ & $0.61 \pm 0.45^{\mathrm{c}, \mathrm{A}}$ & 89.65 & $0.38 \pm 0.06^{\mathrm{c}, \mathrm{A}}$ & 96.10 & $0.61 \pm 0.39 \mathrm{~b}, \mathrm{~A}$ & 96.46 \\
\hline
\end{tabular}

Mean values within a raw (capital letters) and a column (small letters) with the same letter are not significantly different at $p<0.05$ using Duncan's multiple range test. The first letter of the alphabet for the highest values, the next for statistically significant decreasing values. $n=18$. MN—mean number of trophozoites; GI—growth inhibition.

Table 7. Effect of extract from Eryngium planum shoot and root in vitro culture on inhibition of Acanthamoeba trophozoites during four days treatment.

\begin{tabular}{|c|c|c|c|c|c|c|}
\hline \multirow{3}{*}{$\begin{array}{c}\text { Extracts } \\
\text { Concentration }\end{array}$} & \multicolumn{6}{|c|}{ Duration of Treatment [days] } \\
\hline & \multicolumn{2}{|c|}{ 2nd Day } & \multicolumn{2}{|c|}{ 3rd Day } & \multicolumn{2}{|c|}{ 4th Day } \\
\hline & $\mathrm{MN} \pm \mathrm{SD}$ & GI [\%] & $\mathrm{MN} \pm \mathrm{SD}$ & GI [\%] & $\mathrm{MN} \pm \mathrm{SD}$ & GI $[\%]$ \\
\hline Control & $10.50 \pm 1.83^{\mathrm{a}, \mathrm{B}}$ & 0 & $20.67 \pm 3.37^{\mathrm{a}, \mathrm{A}}$ & 0 & $25.12 \pm 4.34^{\mathrm{a}, \mathrm{A}}$ & 0 \\
\hline $0.5 \mathrm{mg} / \mathrm{mL}$ & $4.00 \pm 2.57^{\mathrm{b}, \mathrm{B}}$ & 61.91 & $10.92 \pm 3.00^{\mathrm{b}, \mathrm{A}}$ & 47.17 & $13.80 \pm 4.55^{\mathrm{b}, \mathrm{A}}$ & 46.07 \\
\hline $2.5 \mathrm{mg} / \mathrm{mL}$ & $3.39 \pm 2.31 \mathrm{~b}, \mathrm{~A}$ & 67.72 & $4.00 \pm 2.31^{\mathrm{c}, \mathrm{A}}$ & 80.65 & $4.33 \pm 1.93^{\mathrm{c}, \mathrm{A}}$ & 82.77 \\
\hline $5.0 \mathrm{mg} / \mathrm{mL}$ & $2.35 \pm 1.35^{\mathrm{b}, \mathrm{A}}$ & 77.62 & $1.56 \pm 1.30^{\mathrm{c}, \mathrm{A}}$ & 92.02 & $1.50 \pm 1.17 \mathrm{c}, \mathrm{A}$ & 94.03 \\
\hline Root culture & $\mathrm{MN} \pm \mathrm{SD}$ & GI $[\%]$ & $\mathrm{MN} \pm \mathrm{SD}$ & GI [\%] & $\mathrm{MN} \pm \mathrm{SD}$ & GI $[\%]$ \\
\hline Control & $9.18 \pm 2.26^{a, C}$ & 0 & $21.89 \pm 4.15^{\mathrm{a}, \mathrm{B}}$ & 0 & $32.89 \pm 4.14^{\mathrm{a}, \mathrm{A}}$ & 0 \\
\hline $0.5 \mathrm{mg} / \mathrm{mL}$ & $6.06 \pm 1.95^{\mathrm{a}, \mathrm{B}}$ & 33.99 & $11.47 \pm 4.26^{\mathrm{b}, \mathrm{AB}}$ & 47.61 & $18.33 \pm 2.62^{\mathrm{b}, \mathrm{A}}$ & 44.27 \\
\hline $2.5 \mathrm{mg} / \mathrm{mL}$ & $3.68 \pm 1.03^{\mathrm{b}, \mathrm{B}}$ & 59.92 & $4.35 \pm 2.35^{\mathrm{c}, \mathrm{B}}$ & 80.13 & $10.83 \pm 2.80^{c, A}$ & 67.08 \\
\hline $5.0 \mathrm{mg} / \mathrm{mL}$ & $2.11 \pm 1.59^{\mathrm{b}, \mathrm{A}}$ & 77.02 & $1.57 \pm 1.06^{\mathrm{c}, \mathrm{A}}$ & 92.83 & $4.41 \pm 2.30^{\mathrm{d}, \mathrm{A}}$ & 86.61 \\
\hline
\end{tabular}

Mean values within a raw (capital letters) and a column (small letters) with the same letter are not significantly different at $p<0.05$ using Duncan's multiple range test. The first letter of the alphabet for the highest values, the next for statistically significant decreasing values. $n=18$. MN—mean number of trophozoites; GI-growth inhibition. 
Table 8. Determination of $\mathrm{IC}_{50}[\mathrm{mg} / \mathrm{mL}]$ for the studied extracts of Eryngium extracts on Acanthamoeba trophozoites proliferation in the culture medium.

\begin{tabular}{ccccc}
\hline $\begin{array}{c}\text { Eryngium } \\
\text { Species }\end{array}$ & In Vitro Culture & $\begin{array}{c}\text { IC50 2nd Day } \\
{[\mathbf{m g} / \mathbf{m L}]}\end{array}$ & $\begin{array}{c}\text { IC50 3rd Day } \\
{[\mathbf{m g} / \mathbf{m L}]}\end{array}$ & $\begin{array}{c}\text { IC50 4th Day } \\
{[\mathbf{m g} / \mathbf{m L}]}\end{array}$ \\
\hline \multirow{2}{*}{ E. campestre } & shoot culture & 0.72 & 0.80 & 1.05 \\
& root culture & $>5.00$ & 3.20 & 2.00 \\
\hline \multirow{2}{*}{ E. maritimum } & shoot culture & 3.70 & 2.90 & 2.60 \\
& root culture & 1.85 & 1.15 & 1.00 \\
\hline \multirow{2}{*}{ E. planum } & shoot culture & 0.45 & 0.25 & 0.70 \\
& root culture & 1.50 & 0.60 & 0.75 \\
\hline
\end{tabular}

In the case of E. maritimum, a stronger effect was observed for in vitro root culture (Table 6). Generally, the higher sample concentration was applied, the more effective activity was observed in comparison with the control during the same time interval. It can be noticed that the activity of both shoot and root extracts $(0.5 \mathrm{mg} / \mathrm{L}$ and $2.5 \mathrm{mg} / \mathrm{L})$ increased with the time of treatment, while the activity of the extract of a higher concentration $(5.0 \mathrm{mg} / \mathrm{L})$ remained at a statistically similar level.

In the case of E. planum, a strong effect was observed both for in vitro shoot and root culture (Table 7). Generally, no statistical differences were observed in the activity of the extracts between the higher $(2.5 \mathrm{mg} / \mathrm{L})$ and the highest concentration $(5.0 \mathrm{mg} / \mathrm{L})$ during the same time interval. Moreover, no statistical differences were observed in the activity of the extracts between the 3rd and 4th day taking into consideration the highest concentrations of the extract. On the fourth day of exposure of trophozoites to the shoot culture extract, regardless of the concentration, cysts appeared.

The lowest $\mathrm{IC}_{50}$ index was calculated for the E. planum shoot culture extract. On the second day of Acanthamoeba trophozoites treatment, the $\mathrm{IC}_{50}$ value was $0.25 \mathrm{mg} / \mathrm{mL}$. During the entire treatment period, the lowest $\mathrm{IC}_{50}$ was obtained for the extract of $E$. campestre shoot culture and shoot and root cultures of E. planum (Table 8).

The obtained extracts were assessed for antiprotozoal activity against Acanthamoeba sp. The strength of biological activity of the extracts correlated with the content of phenolic compounds. The highest amounts of phenolic acids and flavonoids were confirmed for E. planum root extract, followed by E. planum and E. campestre shoot extracts, which was correlated with the results of $\mathrm{IC}_{50}$ for those extracts. The conducted studies showed a strong correlation between the activity of Eryngium species extracts on Acanthamoeba trophozoites proliferation with the sum of flavonoids and phenolic acids determined by using the HPLC-DAD method ( $\mathrm{R}^{2}$ in the range 0.7478-0.8424) (Figure 2). This effect of the synergistic action of phenolic compounds may be due to the presence in the plant materials of chlorogenic acid [26], rosmarinic acid [27], and quercetin [28], which are well known as amoebicidal agents.

Previously, the evaluation of the amoebicidal activity of E. planum was conducted for the extracts and fractions obtained from leaves and roots of intact plants. Among different fractions from leaf and root ethanolic extracts: flavonoid, flavonoid-saponin, and saponin assayed for the antiamoebic activity studies, the phenolic acid fraction from roots at the concentration of $5.0 \mathrm{mg} / \mathrm{L}$ showed the activity on the A. castellanii trophozoites. According to the authors, this activity is correlated with the antioxidant activity of phenolic acids. This class of phenolic compounds may cause damage to the plasma membrane, which results in a leakage of intracellular constituents from the cell [29]. For the alpine species (Eryngium alpinum), the activity of the extract from the leaves of intact plants and in vitro shoot cultures was compared. The extract of shoots multiplied in vitro showed the highest antiamoebicidal effect already on the second day of treatment: the percent of inhibition of trophozoites was $81.14 \%, 66.38 \%$, and $54.99 \%$ at the concentrations of $5 \mathrm{mg} / \mathrm{mL}, 2.5 \mathrm{mg} / \mathrm{mL}$, and $0.5 \mathrm{mg} / \mathrm{mL}$, respectively. The extract from shoots of intact plants at a dose of 0.5 and $2.5 \mathrm{mg} / \mathrm{mL}$ weakly inhibited the development of trophozoites [30]. 


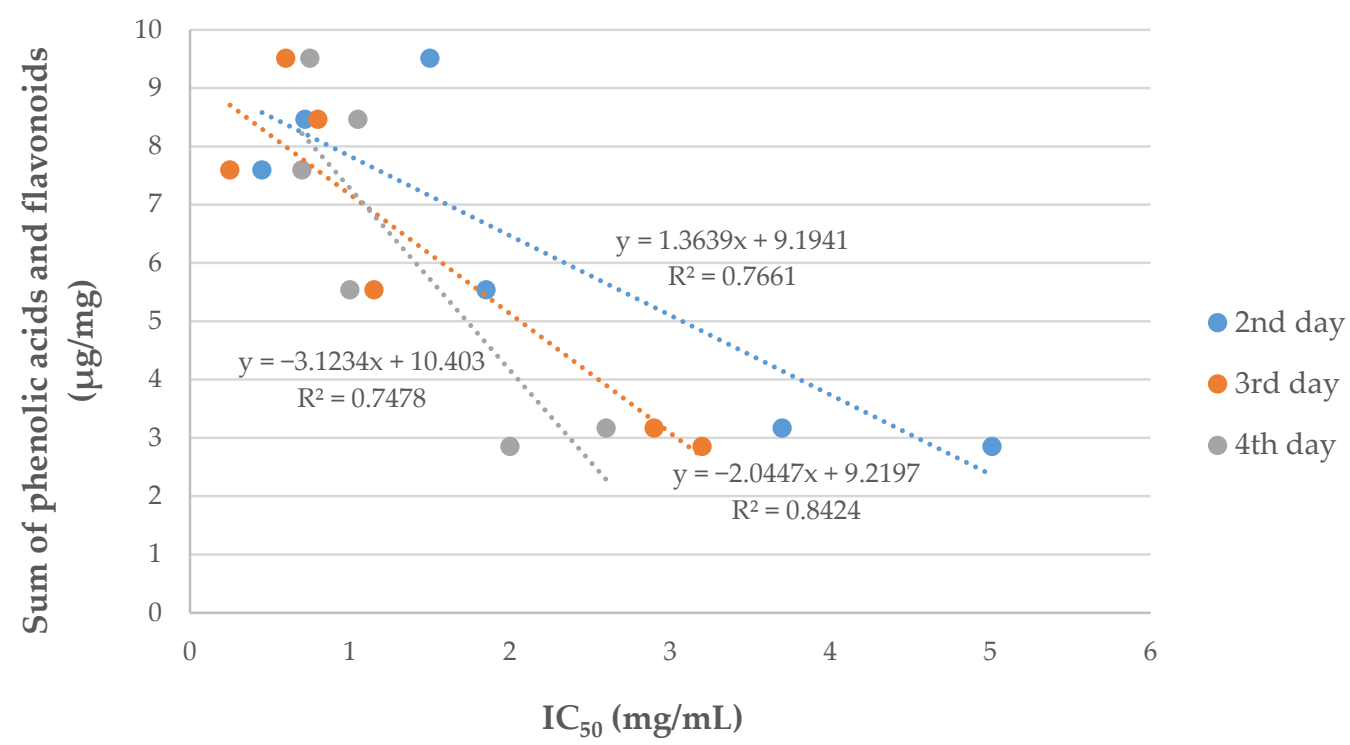

Figure 2. Correlation between $\mathrm{IC}_{50}$ values and the sum of phenolic acids and flavonoids determined by HPLC method in Eryngium species.

In our experiment, on the fourth day of exposure of trophozoites to the E. planum shoot culture extract, regardless of the concentration, cysts appeared. The parasite has a strong ability to transform into a dormant cyst stage under stressful conditions [8]. Unfortunately, the cyst walls provide a physical barrier for drugs/extracts/fraction or isolated compounds to target amoeba residing within the shell [31]. In the authors opinion, the discovery of various antiacanthamoebic natural products tested in vitro has not been able to enter the drug development process due to their inefficacy against the cysts.

In the literature on the subject, more scientific information on the plant extracts with the amoebicidal or amoebistatic activity against pathogenic strains of Acanthamoeba spp. can be found regarding the extracts from aerial parts of Centaurea bella, C. daghestanica, Rhaponticum pulchrum, Tanacetum vulgare [32], roots and leaves of Rubus chamaemorus, Pueraria lobata, Solidago spp. [33], leaves and calluses of Passiflora spp. [34], calluses, leaves, and roots of micropropagated plantlets of Chaenomeles japonica [35]. Buddleia cordata is a plant of potential and practical use in the treatment of acanthamoebosis-the therapy uses extracts from the roots, bark, and fruits of this plant. It was noted that the chemically active substance in these extracts is linarin, which belongs to the flavones [36]. Flavonoids and phenolic acids are the phenolic compounds that may be found to exert a strong antiprotozoal effect $[26-28,37]$. The problem of treating acanthamoebiasis with the use of substances of plant origin has recently become very popular-the therapeutic properties of other plants are still being investigated.

To our knowledge, this is the first report on the amoebicidal activity of E. campestre, E. maritimum, and E. planum extracts from biomass produced by biotechnological methods.

\section{Materials and Methods}

\subsection{Plant Material}

Fruits of E. campestre were collected from steppe reserve Owczary (Sękowa, Poland) and of E. planum from natural habitats in Poland (Lukaszewo, Kuyavian-Pomeranian province). Primary explants-shoot fragments with lateral buds of. E. maritimum-were shared by the Botanical Garden of Adam Mickiewicz University in Poznan (Poland). The appropriate explants were surface disinfected and introduced to the in vitro conditions according to the procedure adopted by Thiem et al. [10] and Kikowska et al. [11,12]. 


\subsection{Shoot Cultures}

Shoots were multiplied through an axillary branching method by repetitive transfer of suitable explant. Multishoots were divided into single shoots and transferred to new medium solidified with $7.6 \mathrm{~g} / \mathrm{L}$ agar with the same supplementation every 5-6 weeks. E. campestre, E. planum, and E. maritimum were multiplied on MS medium [38] enriched with 6-benzyladenine (BA, $1.0 \mathrm{mg} / \mathrm{L}$ ) and indole-3-acetic acid (IAA, $1.0 \mathrm{mg} / \mathrm{L}$ ). The percentage of explants that proliferated buds, total number of shoots per explant, and length of shoots were recorded after 6 weeks of 18-19th subculture. Multiplication of shoots was replicated three times at least with 10 explants per treatment. The shoots were multiplied according to the procedure adopted by Thiem et al. [10] and Kikowska et al. [11,12].

\subsection{Root Cultures}

Root fragments with tips (1.0-2.0 cm long) obtained from axenic plantlets were used for adventitious root cultures initiation. The explants were transferred into MS liquid media with an auxin IAA $(1.0 \mathrm{mg} / \mathrm{L})$. The cultures were maintained on a rotary shaker at $100 \mathrm{rpm}$. Root cultures were inoculated into the same liquid media and the same culture conditions as the one employed for routine subculturing were applied. The root cultures were subcultured at 5-week intervals. The roots were maintained according to the procedure adopted by Thiem et al. [10] and Kikowska et al. [11,12].

\subsection{Culture Conditions}

The shoot cultures were grown under artificial light $-55 \mu \mathrm{mol} / \mathrm{m}^{2} \mathrm{~s}(16 \mathrm{~h}$ light $/ 8 \mathrm{~h}$ dark photoperiod) and the root cultures were cultured in the darkness. Both cultures were maintained at a temperature of $21^{\circ} \mathrm{C} \pm 2{ }^{\circ} \mathrm{C}$.

\subsection{HPLC-DAD Analysis}

For chromatographic analyses, the fresh biomass of in vitro shoots and roots of Eryngium species (E. campestre, E. maritimum, E. planum), was dried at $40{ }^{\circ} \mathrm{C}$ for $24 \mathrm{~h}$ to a constant weight. For extract preparation, dried and pulverized material samples, $0.5 \mathrm{~g}$ dry weight (DW) each, were extracted by sonication (Polsonic ${ }^{\circledR} 3$, Warsaw, Poland) in methanol $(5 \mathrm{~mL}$ ) two times for $30 \mathrm{~min}$. The validated HPLC-DAD method was employed for the analyses of phenolic acids and flavonoids in the extracts (according to Ellnain-Wojtaszek and Zgorka [39] and Szopa et al. [40]). The HPLC-DAD apparatus and conditions were profiled by us previously $[40,41]$ The recognition of compounds was carried out on the comparison of UV spectra $(\lambda=200-400 \mathrm{~nm})$ and retention time of the reference substances. Moreover, the internal standard method was used. The quantification of compounds was performed by peak measurements and the standard curves method. The reference compounds were bought from Sigma-Aldrich (Saint Louis, MO, USA) (phenolic acids: 3,4-dihydroxyphenylacetic acid, caftaric acid, caffeic acid, chlorogenic acid, 2-coumaric, 3-coumaric, 4-coumaric acids, ferulic acid, 4-feruloylquinic acid, gallic acid, gentisic acid, hydrocaffeic acid, 4-dihydroxybenzoic, 4-hydroxybenzoic acid, isochlorogenic acid, isoferulic acid, neochlorogenic acid, protocatechuic acid, rosmarinic acid, salicylic acid, sinapic acid, syringic acid and vanillic acid, and benzoic and cinnamic acids (precursors of phenolic acids); and flavonoids-aglycones: isorhamnetin kaempferol, luteolin, quercetin, rhamnetin, and myricetin and glycosides: apigetrin, astragalin cynaroside, hyperoside, populnin, quercitrin, rutoside, trifolin, and vitexin).

\subsection{Total Phenolics Content}

The content of the sum of polyphenols was determined with the Folin-Ciocalteu (Sigma-Aldrich, Saint Louis, MO, USA) reagent according to the modified method of Meng et al. [25]. The dried and weighed plant material (shoots and roots from in vitro cultures and intact plants) was extracted four times in $70 \%(v / v) \mathrm{MeOH}$ in a water bath, under reflux, at a temperature of $95{ }^{\circ} \mathrm{C}$, each time for $1 \mathrm{~h}$. The obtained extracts are combined and concentrated to a volume of $25 \mathrm{~mL}$ on a vacuum evaporator at $40^{\circ} \mathrm{C}$. Briefly, $0.1 \mathrm{~mL}$ 
of each extract or gallic acid solution at different concentrations $(0.02-0.08 \mathrm{mg} / \mathrm{mL})$ was mixed with $0.1 \mathrm{~mL}$ of Folin-Ciocalteu reagent and allowed to react at room temperature for $3 \mathrm{~min}$. Finally, $1.0 \mathrm{~mL}$ of aqueous solution of sodium carbonate $(7.0 \%, w / v)$ was added, and the mixture was incubated in the dark at room temperature for $60 \mathrm{~min}$. The blank sample contained water instead of the extract or gallic acid solution. From each extract, three samples were prepared, from each four analyzes were performed. The measurements were made at the wavelength $\lambda=760 \mathrm{~nm}$, in the Perkin-Elmer Lambda (Norwalk, CT, USA) $35 \mathrm{UV} /$ VIS apparatus. Gallic acid (GA) was used as an external standard to plot the calibration curve $\left(y=94.065 x+0.0331, R^{2}=0.9999\right)$ and the results were expressed as milligrams of GA equivalent per gram of dry weight of the plant material. The values were expressed as the mean of six replications $\pm \mathrm{SD}$.

\subsection{Antiamoebic Activity}

In this study, the Acanthamoeba sp. strain Ac55 (isolated from a patient with keratitis, T4 genotype) deposited in GenBank (NCBI) under accession number KP120880 was used. The amoebae were axenically cultured on a liquid medium containing $2 \%$ Bacto-Casitone. The methanolic extracts were dissolved in $50 \mu \mathrm{L}$ of dimethylsulfoxide (DMSO) and then diluted with distilled water to obtain the appropriate concentrations. These dilutions were added to the axenic culture of amoebae containing $5 \times 10^{4}$ cells $/ \mathrm{mL}$ at the concentrations of $0.5-5 \mathrm{mg} / \mathrm{mL}$. The increase or decrease in the number of amoebae was checked at $24 \mathrm{~h}$ intervals for three days (2nd, 3rd, 4th) in a Thoma hemocytometer chamber. The control consisted of cultured trophozoites without extracts. The relationship between fraction concentration and the time of treatment of trophozoite cultures was investigated. The method was described by us previously [29-34].

\subsection{Statistical Analysis}

The data from biotechnological, phytochemical, and biological experiments were analyzed using a one-way analysis of variance (ANOVA) and the statistical significance was determined using Duncan's post hoc test ( $p$-value $<0.05)$. All the analyses were conducted employing STATISTICA v. 13 (StatSoft, Inc. 2015, Kraków, Poland).

\section{Conclusions}

Shoot and root in vitro cultures of Eryngium species may be considered a valuable alternative source of biomass that is rich in valuable bioactive compounds such as phenolic acids and flavonoids. The content of the sum of polyphenols in Eryngium species was always higher in the biomass from in vitro cultures than in the analogous organs of ground plants of each species. The strength of antiprotozoal activity of extracts correlated with the content of phenolic compounds determined in them. The results suggest that the extracts from Eryngium spp. may be promising candidates for Acanthamoeba treatment.

Author Contributions: Conceptualization, M.K. and B.T.; methodology, M.K., J.C.-K., M.D. and A.S.; software, M.K., J.C.-K., M.D. and A.S.; validation, A.S.; formal analysis, M.K., J.C.-K. and A.S.; investigation, M.K., J.C.-K., M.D. and A.S. resources, B.T.; writing—original draft preparation, M.K.; writing-review and editing, J.C.-K., A.S., A.B. and H.E.; visualization, M.K., M.D. and A.S.; supervision, A.B. and H.E.; funding acquisition, B.T., H.E. and M.D. All authors have read and agreed to the published version of the manuscript.

Funding: This research received no external funding.

Institutional Review Board Statement: Not applicable.

Informed Consent Statement: Not applicable.

Data Availability Statement: The data presented in this study are available from the authors.

Conflicts of Interest: The authors declare no conflict of interest.

Sample Availability: Samples of the biomass/extracts are available from the authors. 


\section{References}

1. Calvino, C.I.; Martinez, S.G.; Downie, S.R. The evolutionary history of Eryngium (Apiaceae, Saniculoideae): Rapid radiations, long distance dispersals and hybridizations. Mol. Phylogenet. Evol. 2008, 46, 1129-1150. [CrossRef]

2. Wörz, A.; Diekmann, H. Classification and evolution of the genus Eryngium, L. (Apiaceae Saniculoideae): Results of fruit anatomical and petal morphological studies. Plant. Div. Evol. 2010, 128, 387-408. [CrossRef]

3. Tutin, T.G.; Heywood, V.H.; Burges, N.A.; Moore, D.M.; Valentine, D.H.; Walters, S.M.; Webb, D.A. Rosaceae to Umbelliferae. In Flora Europaea; Tutin, T.G., Ed.; Cambridge University Press: Cambridge, UK, 1968; Volume 2.

4. Wang, P.; Su, Z.; Yuan, W.; Deng, G.; Li, S. Phytochemical Constituents and Pharmacological Activities of Eryngium, L. (Apiaceae). Pharm. Crop. 2012, 3, 99-120. [CrossRef]

5. $\quad$ Erdem, S.A.; Nabavi, S.F.; Orhan, I.E.; Daglia, M.; Izadi, M.; Nabavi, S.M. Blessings in disguise: A review of phytochemical composition and antimicrobial activity of plants belonging to the genus Eryngium. DARU 2015, 23, 1-22. [CrossRef] [PubMed]

6. Kikowska, M.; Thiem, B. In vitro systems of selected Eryngium species (E. planum, E. campestre, E. maritimum, and E. alpinum) for studying production of desired secondary metabolites (phenolic acids, flavonoids, triterpenoid saponins, and essential oil). In Plant Cell and Tissue Differentiation and Secondary Metabolites. Fundamentals and Applications; Reference Series in Phytochemistry; Ramawat, K.G., Ekiert, H.M., Goyal, S., Eds.; Springer: Cham, Switzerland; Heidelberg, Germany, 2020; pp. 1-33.

7. Derda, M.; Hadaś, E. The use of phytotherapy in diseases caused by parasitic protozoa. Acta. Parasitol. 2015, 60, 1-8. [CrossRef]

8. Elsheikha, H.M.; Siddiqui, R.; Khan, N.A. Drug Discovery against Acanthamoeba Infections: Present Knowledge and Unmet Needs. Pathogens 2020, 9, 405. [CrossRef] [PubMed]

9. Kayser, O.; Kiderlen, A.F.; Croft, S.L. Natural products as antiparasitic drugs. Parasitol. Res. 2003, 90 (Suppl. 2), S55-S62. [CrossRef]

10. Thiem, B.; Kikowska, M.; Krawczyk, A.; Więckowska, B.; Sliwinska, E. Phenolic acid and DNA contents of micropropagated Eryngium planum L. Plant Cell Tiss. Organ Cult. 2013, 114, 197-206. [CrossRef]

11. Kikowska, M.; Thiem, B.; Sliwinska, E.; Rewers, M.; Kowalczyk, M.; Stochmal, A.; Oleszek, W. The effect of nutritional factors and plant growth regulators on micropropagation and production of phenolic acids and saponins from plantlets and adventitious root cultures of Eryngium maritimum L. J. Plant. Growth Regul. 2014, 33, 809-819. [CrossRef]

12. Kikowska, M.; Thiem, B.; Sliwinska, E.; Rewers, M.; Kowalczyk, M.; Stochmal, A.; Długaszewska, J. Micropropagation of Eryngium campestre L. via shoot culture provides valuable uniform plant material with enhanced content of phenolic acids and antimicrobial activity. Acta Biol. Cracov. Bot. 2016, 58, 43-56. [CrossRef]

13. Makunga, N.P.; Jäger, A.K.; van Staden, J. Micropropagation of Thapsia garganica-A medicinal plants. Plant Cell. Rep. 2003, 21, 967-973. [CrossRef]

14. Sliva, Š.; Viehmannova, I.; Vitamvas, J. Micropropagation and morphogenesis of Arracacha (Arracacia xanthorrhiza Bancroft). Agric. Trop. Subtrop. 2010, 43, 206-211.

15. Jana, S.; Shekhawat, G.S. In vitro regeneration of Anethum graveolens, antioxidative enzymes during organogenesis and RAPD analysis for clonal fidelity. Biol. Plant. 2012, 56, 9-14. [CrossRef]

16. Rahmat, E.; Kang, Y. Adventitious root culture for secondary metabolite production in medicinal plants: A Review. J. Plant. Biotech. 2019, 46, 143-157. [CrossRef]

17. Le Clarie, E.; Schwaiger, S.; Banaigs, B.; Stuppner, H.; Gafner, F. Distribution of a new rosmarinic acid derivative in Eryngium alpinum L. and another Apiaceae. J. Agric. Food. Chem. 2005, 53, 4367-4372. [CrossRef] [PubMed]

18. Conea, S.; Vlase, L.; Chirila, I. Comparative study on the polyphenols and pectin of three Eryngium species and their antimicrobial activity. Cellul. Chem. Technol. 2016, 50, 473-481.

19. Hiller, K.; Otto, A.; Grundemann, E. Isolation of kaempferol-3-O-(6-O-beta-D-glucopyranosyl)-beta-D-galactopyranoside, a new flavonol glycoside from Eryngium planum L. 34. On the knowledge of the constituents of some Saniculoideae. Pharmazie 1980, 35, 113-114.

20. Leokadia, S.P. Kaempferol 3,7-dirhamnoside from Eryngium planum L. Z Chem. 1983, 23, 294-295.

21. Kartnig, T.; Wolf, J. Flavonoide aus den oberirdischen Teilen von Eryngium campestre. Planta Med. 1993, 59, 285. [CrossRef]

22. Hohmann, J.; Páll, Z.; Günther, G.; Máthé, I. Flavonolacyl glycosides of the aerial parts of Eryngium campestre. Planta Med. 1997, 63, 96. [CrossRef]

23. Hawas, U.W.; El-Kassem, L.A.T.; Award, H.; Taie, H. Anti-Alzheimer, antioxidant activities and flavonol glycosides of Eryngium campestre L. Curr. Chem. Biol. 2013, 7, 188-195. [CrossRef]

24. Hiller, K.; Pohl, B.; Franke, P. Flavonoid spectrum of Eryngium maritimum L. 35. Components of Saniculoideae. Pharmazie 1981, 36, 451-452.

25. Meng, C.C.; Jalil, A.M.M.; Ismail, A. Phenolic and Theobromine Contents of Commercial Dark, Milk and White Chocolates on the Malaysian Market. Molecules 2009, 14, 200-209. [CrossRef] [PubMed]

26. Mahboob, T.; Abdul-Majid Azlan, A.-M.; Tan, T.-C.; Samudi, C.; Sekaran, S.-D.; Nissapatorn, V.; Wiart, C. Anti-encystment and amoebicidal activity of Lonicera japonica Thunb. and its major constituent chlorogenic acid in vitro. Asian Pac. J. Trop. Med. 2016, 9 , 866-871. [CrossRef]

27. Bittner Fialová, S.; Kello, M.; Čoma, M.; Slobodníková, L.; Drobná, E.; Holková, I.; Garajová, M.; Mrva, M.; Zachar, V.; Lukáč, M. Derivatization of rosmarinic acid enhances its in vitro antitumor, antimicrobial and antiprotozoal properties. Molecules 2019, 24, 1078. [CrossRef] 
28. Anwar, A.; Ting, E.L.S.; Anwar, A.; ul Ain, N.; Faizi, S.; Shah, M.R.; Khan, N.K.; Siddiqui, R. Antiamoebic activity of plant-based natural products and their conjugated silver nanoparticles against Acanthamoeba castellanii (ATCC 50492). Amb. Expr. 2020, 10, 24. [CrossRef]

29. Derda, M.; Thiem, B.; Budzianowski, J.; Wojt, W.; Wojtkowiak-Giera, A. The evaluation of the amebicidal activity of Eryngium planum extracts. Acta Pol. Pharm. 2013, 70, 1027-1034.

30. Kikowska, M.; Kruszka, D.; Derda, M.; Hadaś, E.; Thiem, B. Phytochemical screening and acanthamoebic activity of shoots from in vitro cultures and in vivo plants of Eryngium alpinum L.-the endangered and protected species. Molecules 2020, $25,1416$. [CrossRef]

31. Anwar, A.; Khan, N.A.; Siddiqui, R. Combating Acanthamoeba spp. cysts: What are the options? Parasit. Vectors. 2018, 11, 26. [CrossRef]

32. Hadaś, E.; Derda, M.; Nawrot, J.; Nowak, G.; Thiem, B. Evaluation of the amoebicidal activities of Centaurea bella, Centaurea daghestanica, Rhaponticum pulchrum and Tanacetum vulgare against pathogenic Acanthamoeba spp. Acta. Pol. Pharm. 2017, 74, $1827-1832$.

33. Derda, M.; Hadaś, E.; Thiem, B. Plant extracts as natural amoebicidal agents. Parasitol. Res. 2008, 104, 705-708. [CrossRef] [PubMed]

34. Hadaś, R.; Ożarowski, M.; Derda, M.; Thiem, B. The use of extracts from Passiflora spp. in helping the treatment of acanthamoebiasis. Acta. Pol. Pharm. 2017, 74, 921-928. [PubMed]

35. Kikowska, M.; Derda, M.; Thiem, B.; Włodarczyk, A.; Długaszewska, J.; Stochmal, A.; Żuchowski, J.; Hadaś, E. Evaluation of antiamoebic and antimicrobial activities in vitro of Chaenomeles japonica (Thunb.) Lindl. ex spach extracts. Acta. Biol. Cracov. Ser. Bot. 2019, 61, 47-58.

36. Rodríguez-Zaragoza, S.; Ordaz, C.; Avila, G.; Muñoz, J.L.; Arciniegas, A.; Romo de Vivar, A. In vitro evaluation of the amebicidal activity of Buddleia cordata (Loganiaceae, H.B.K.) on several strains of Acanthamoeba. J. Ethnopharmacol. 1999, 66, 327-334. [CrossRef]

37. Wei, H.E.; Yeng, C.Y.; Mahboob, T.; Ling, L.C.; Raju, C.S.; Barusrux, S.; Nissapatorn, V. Natural Products: Alternative Therapeutic Compounds Against Acanthamoeba spp. Asian. J. Pharm. 2019, 3, 29-38.

38. Murashige, T.; Skoog, F. A revised medium for rapid growth and bioassays with tobacco cultures. Physiol. Plant. 1962, 15, 473-497. [CrossRef]

39. Ellnain-Wojtaszek, M.; Zgorka, G. High-performance liquid chromatography and thin-layer chromatography of phenolic acids from Ginkgo biloba L. leaves collected within vegetative period. J. Liq. Chromatogr. Relat. Technol. 1999, 22, 1457-1471. [CrossRef]

40. Szopa, A.; Kokotkiewicz, A.; Kubica, P.; Banaszczak, P.; Wojnatowska-Krośniak, A.; Krośniak, M.; Marzec-Wróblewska, U.; Badura, A.; Zagrodzki, P.; Buciński, A.; et al. Comparative analysis of different groups of phenolic compounds in fruit and leaf extracts of Aronia sp.: A. melanocarpa, A. arbutifolia, and A.×prunifolia and their antioxidant activities. Eur. Food Res. Technol. 2017, 243, 1645-1657. [CrossRef]

41. Szopa, A.; Kokotkiewicz, A.; Bednarz, M.; Luczkiewicz, M.; Ekiert, H. Studies on the accumulation of phenolic acids and flavonoids in different in vitro culture systems of Schisandra chinensis (Turcz.) Baill. using a DAD-HPLC method. Phytochem. Lett. 2017, 20, 462-469. [CrossRef] 